Supporting Information

\title{
Multifunctional Nano-architecture for Biomedical
}

\section{Applications}

Dongling Ma,${ }^{\dagger}$ Jingwen Guan, ${ }^{\dagger}$ Fraņois Normandin, ${ }^{\ddagger}$ Stephane Denommee ${ }^{\dagger}$ Gary Enright, ${ }^{\dagger}$

$$
\text { Teodor Veres, }{ }^{\ddagger} \text { and Benoit Simard }{ }^{*}, \dagger
$$

National Research Council of Canada, Steacie Institute for Molecular Sciences, 100 Sussex Drive, Ottawa, ON K1A OR6, Canada, and National Research Council of Canada, Industrial Materials Institute, 75 de Mortagne Boulevard, Boucherville, QC J4B 6Y4, Canada

*Corresponding author. Tel: 1613 990-0977. E-mail: Benoit.Simard@nrc-cnrc.gc.ca.

${ }^{\dagger}$ National Research Council of Canada, Steacie Institute for Molecular Sciences

$¥$ National Research Council of Canada, Industrial Materials Institute 


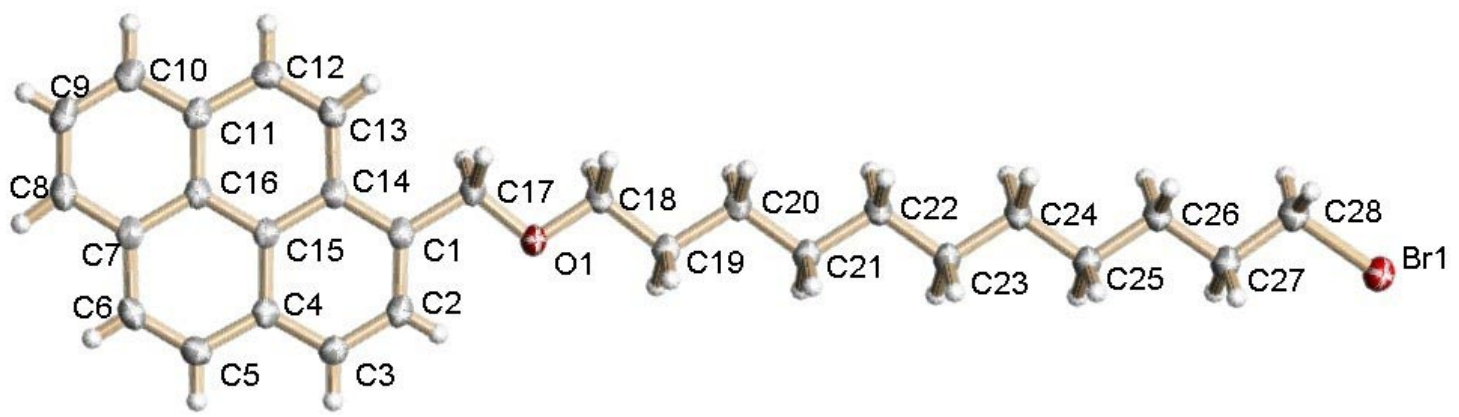

Figure S1. X-ray crystal structure of 1-pyrenemethoxybromoundecane (Br-Py). 